\title{
Habitação de Interesse Social no Brasil: análise sobre o tema nos currículos mínimos de 1962 e 1969 dos cursos de Arquitetura e Urbanismo
}

\author{
Alexsandro Tenório Porangaba*
}

Resumo Este artigo analisa os currículos mínimos dos cursos de Arquitetura e Urbanismo no Brasil instituídos em 1962 e 1969, a fim de identificar como o tema da Habitação de Interesse Social (HIS) foi inserido no campo de formação profissional dos arquitetos nestes documentos. A partir de uma investigação histórico-documental, a análise constata que o referido tema foi intencionalmente negligenciado no currículo de 1962 e posto na condição de programa específico, portanto, não fundamental, no currículo de 1969. Fatos que, historicamente, legitimam o desprestígio do tema nos ateliês de projeto dos cursos de graduação.

Palavras-chave: Habitação de Interesse Social (HIS), currículo mínimo, ensino de arquitetura e urbanismo.

\section{Housing social in Brazil: analysis on the subject in the minimum curricula of 1962 and 1969 of the courses of Architecture and Urbanism}

\begin{abstract}
This article analyzes the minimal curricula of the Architecture and Urbanism courses in Brazil instituted in 1962 and 1969, in order to identify how the theme of Social Interest Housing (HIS) was inserted in the field of professional training of architects in these documents. Based on a historical-documentary research, the analysis shows that the subject was intentionally neglected in the 1962 curriculum and placed in the condition of a specific, and therefore not fundamental, program in the 1969 curriculum. Facts that historically legitimize the deprestige of the subject In the design workshops of the undergraduate courses.
\end{abstract}

Key words: housing of social interest, minimum curriculum, architecture and urbanism teaching.

\begin{abstract}
Vivienda social en Brasil:
análisis de la materia en el plan de estudios mínimo 1962 y 1969 de los cursos de Arquitectura y Urbanismo
\end{abstract}

Resumen Este artículo analiza los planes de estudios mínimo de cursos de arquitectura y urbanismo en Brasil instituyó en 1962 y 1969 con el fin de identificar cómo se inserta el tema de la Vivienda Social en el campo de entrenamiento de los arquitectos en estos documentos. A partir de una investigación documental histórico, el análisis señala que ese tema fue descuidado intencionalmente en el plan de estudios de 1962 y puesto en condición programa específico, por lo que no es esencial, en 1969. Datos de plan de estudios que legitimar históricamente objeto de descrédito en los estudios de diseño de cursos de graduación.

Palavras clave: vivienda social, plan de estudios mínimo, enseñar arquitectura y urbanismo. 
*Alexsandro Tenório Porangaba é Arquiteto e Urbanista, professor no Departamento de Engenharia Civil (DEC) da Universidade Federal de Sergipe (UFS). ORCID: <http://orcid.org/00000002-6124-8013>

1 Neste trabalho, o termo utilizado para se referir a habitação destinada para a população de menor rendimento financeiro será Habitação de Interesse Social, termo primeiramente utilizado pelo extinto Banco Nacional de Habitação (BNH).

2 Este artigo evidencia os primeiros resultados da pesquisa de doutoramento em curso no PPGAU/UFBA sob orientação da Profa Dra Naia Alban Suares e coorientação do Prof. Nivaldo Vieira de Andrade Junior.
N as antigas civilizações, a cultura e a tecnologia disponível eram os principais fatores que determinavam os padrões habitacionais, de modo a influenciar no tamanho, forma, divisões internas, acessos e localização. Atualmente, esses padrões são determinados pela política e a economia nas cidades urbanizadas. Ao se relacionar com o fator econômico, a habitação assume diferentes características e denominações conforme o poder aquisitivo do usuário a quem se destina: casa, residência, mansão, entre outras. No entanto, quando se trata de habitações destinadas aos extratos sociais sem ou com os menores rendimentos financeiros, essas parecem estar inseridas numa categoria de menor importância que, a depender das políticas públicas ou incentivos privados, recebem distintas definições: Habitação Popular, Habitação Social, Habitação de Interesse Social, Habitação Mínima, Habitação Econômica, Habitação de Baixo Custo e até mesmo Habitação de Mercado Popular.

Considerando, historicamente, a realidade brasileira no quesito produção de Habitação de Interesse Social' ${ }^{1}$ (HIS), observa-se que a mesma é tratada de modo distinto entre o campo profissional e o educacional. O campo profissional considerado, se refere a ação pública do governo brasileiro quanto à criação e implementação de políticas públicas direcionados aos trabalhadores de rendimentos mais baixos, sobretudo a partir dos anos de 1930, bem como a atuação de arquitetos na elaboração de projetos arquitetônicos para esse segmento populacional. Para o referido campo, a HIS se apresentava como um investimento necessário, diante da realidade do país, marcada pela mudança do sistema econômico de agrário-exportador para urbano-industrial, e pela migração campocidade de uma quantidade significativa de pessoas em busca de novas oportunidades de trabalho e moradia. Para o campo educacional, as disputas em torno do que deveria ser priorizado na formação dos arquitetos e urbanistas, contribuiu para que o projeto de HIS fosse considerado um elemento de pouca visibilidade, secundário.

Alguns pesquisadores e estudiosos da HIS já evidenciaram em suas publicações a pouca importância dada ao tema na historiografia da arquitetura, bem como sua ausência nos bancos escolares (BENETTI, 2012; BONDUKI, 2014; FERREIRA, 2011; BASTO e ZEIN, 2010). Contudo, considerando a situação habitacional do país, cuja demanda por HIS cresce continuamente, uma pergunta se impõe: Por qual motivo as escolas de arquitetura situadas nas grandes cidades não abordam de modo incisivo, na contemporaneidade, o tema da HIS nos ateliês de projeto de arquitetura e no currículo de graduação? As respostas para a questão, podem vir de várias partes, mas uma, em particular, será tratada com especificidade neste artigo ${ }^{2}$, que é o fato dessa realidade ser consequência da histórica conduta dos diferentes agentes que participaram do processo educacional no século XX, quando da construção dos primeiros currículos mínimos, de modo a não legitimar o tema da HIS como um conteúdo obrigatório e primordial na formação do chamado "arquiteto generalista".

Os primeiros currículos mínimos dos cursos de Arquitetura e Urbanismo, estabelecido no país nos anos de 1962 e, posteriormente, reformulado em 1969, são frutos de 
influências políticas, econômicas e sociais que nortearam as caraterísticas - determinadas como fundamentais - na formação profissional do arquiteto. Analisar esses documentos e os fatos históricos, que antecederam seu estabelecimento como artefato social e nacional, é compreender as possíveis razões, contemporâneas, da permanência de determinadas condutas educacionais que aparentam ser imutáveis e intransponíveis quanto a abordagem e/ou inserção de "novos" temas na estrutura curricular dos cursos de graduação em Arquitetura e Urbanismo, como é o caso do Projeto de HIS.

\section{(Des)Encontros intencionais}

O século XX é marcado por significativos acontecimentos ocorridos na área da arquitetura e urbanismo que, até os dias atuais, influenciam a formação superior dos arquitetos e urbanistas no Brasil, tais como: A primeira reforma do currículo da Escola Nacional de Belas Artes (ENBA) em 1931; a busca por autonomia dos cursos de arquitetura e urbanismo; e a criação, a nível nacional, de um currículo mínimo direcionado aos arquitetos e urbanistas. Associados a esses acontecimentos, tem-se ainda os avanços das tecnologias de construção e a participação dos profissionais de arquitetura na elaboração de projetos e na idealização de programas governamentais de provimento à HIS, nos quais pode-se elencar: criação dos Institutos de Aposentadorias e Pensões (IAPs) em 1933 - que conseguiram produzir um número significativo de HIS e a oportunizar a atuação de arquitetos brasileiros - e a criação da Fundação Casa Popular (FCP) em 1946, órgão destinado ao enfrentamento do problema habitacional em âmbito nacional (BONDUKI, 2014; ARAVECHIA BOTAS, 2011). Além desses, já em 1964, diante dos antigos e frágeis programas habitacionais, o governo brasileiro cria o Banco Nacional de Habitação (BNH) que viabilizou uma massiva produção habitacional em todo o território brasileiro.

A partir de 1930, com a expulsão das oligarquias cafeeiras do poder, o governo brasileiro - no comando de Getúlio Vargas - passa a agir em todos os aspectos econômicos do país. Isso, acabou por impactar tanto na educação superior quanto na produção habitacional. No âmbito educacional, Getúlio Vargas, movido pelo ideal de que o país devia fortalecer o ensino tecnicista para concorrer, em nível mundial, com as grandes potências e, também impulsionado pelas insatisfações com os métodos de ensino instaurado na ENBA, nomeia o Arquiteto Lúcio Costa para direção da Escola com o intuito de implementar mudanças na estrutura curricular da instituição (MONTEIRO, 2007).

Naquela ocasião, a arquitetura mundial se encontrava em processo de mudança, a chamada arquitetura moderna estava sendo praticada pelos grandes nomes da arquitetura, sobretudo depois da realização dos Congressos Internacionais de Arquitetura Moderna (CIAM), no final da década de 20. No Brasil, a cultura modernista já havia sido aceita pelos arquitetos nacionais e Lúcio Costa se encontrava entre os simpatizantes. $\mathrm{Na}$ ocasião de sua nomeação como diretor da ENBA, os artistas e arquitetos mais conservadores da instituição não se colocaram em oposição (MONTEIRO, 2007), porém, estes não tinham ainda o conhecimento de que Costa havia se aproximado dos princípios da arquitetura moderna. Assim, a reforma do curso da ENBA se procedeu com o afastamento de alguns docentes academicistas e com a contratação de professores simpatizantes da arte moderna (SEGAWA, 2010; MARAGNO, 2013). 
Na esfera da arquitetura, o debate em torno das exigências da prática e suas conexões com a formação e ensino dos arquitetos estavam em evidências, sobretudo, após a entrada dos preceitos da arquitetura moderna - cujos arquitetos envolvidos com o movimento, dirigiam suas preocupações aos problemas da produção massiva de habitações para os trabalhadores, ou seja, habitações do mínimo nível de vida (BONDUKI, 1994). Esses debates exerceram forte influência nas decisões tomadas por Lúcio Costa enquanto esteve na direção da ENBA. Sobre isso Edgar Graeff já afirmava:

"A luta pela renovação e aperfeiçoamento do ensino de arquitetura no Brasil já se prolonga por quase 50 anos. Vem de uma tomada de posição perfeitamente definida pelo Lúcio Costa, em 1931. Foi a primeira tentativa de atualizar, de colocar o ensino de arquitetura em termos de realidade contemporânea. Tentativa que, naquela época, correspondia muito bem ao que estava ocorrendo no Brasil: tratava-se harmonizar a escola, a universidade, com a vida [...]" (GRAEFF, 1995, p. 36).

Com o advento do pensamento moderno, a exaltação social da arquitetura foi tão expressiva que tornou a casa popular o maior "monumento do século XX" (ARTIGAS, 1986, p.74), porém essa exaltação não se efetivou, formalmente, no ensino da ENBA. O tema da HIS, não estava incluso, oficialmente, nem como disciplina específica e nem como conteúdo obrigatório em qualquer outra disciplina que se relacionasse com a atividade de projeto arquitetônico ou urbanismo (BRASIL, 1931). Apesar dessa constatação, segundo Ernani Vasconcelos, ex-aluno da ENBA na época de Lucio Costa, a habitação popular ocupou lugar de destaque no ensino: "A Torre de Pensamento às margens do Rio Sagrado cedeu lugar à habitação popular" (VASCONCELOS apud CAVALCANTI, 2006, p. 126). Além dele, o arquiteto Abelardo de Souza, também formado pela ENBA, depõe que a reforma de Lúcio Costa foi total. Conforme o arquiteto, os alunos iniciantes se demonstravam bastante entusiasmado, visto que ao invés de projetarem copiando pórticos e frontões, passaram a estudar "[...] temas mais práticos como a "casa mínima", postos de gasolina, grupos escolares, equipamentos de cozinhas e banheiros" (SOUZA, 1978, p. 27). Conforme os relatos, percebe-se que o tema da HIS, apesar da ausência de obrigatoriedade oficial, era estudado na Escola, numa espécie de "currículo informal".

No ano que marca a aprovação da primeira regulamentação profissional dos arquitetos no Brasil, Decreto ${ }^{\circ} 23.569$ de 1933, passa a funcionar no país o Instituto de Aposentadoria e Pensões - IAP. Os IAPs foram os primeiros órgãos públicos a promover HIS no país, mas, essa produção não contemplava os que mais necessitavam de habitação, ou seja, os trabalhadores informais, aqueles que não possuíam carteira assinada, e os trabalhadores da zona rural, como destaca Bonduki:

"Os trabalhadores com carteira assinada, associados aos IAPS, tinham direito a uma proteção social que garantia, além das aposentadorias e pensões, assistência, serviços de saúde e a possibilidade de alugar uma unidade em um conjunto residencial ou obter um financiamento para construir uma moradia" (BONDUKI, 2014, p.141).

Apesar da importância dos IAPs e suas respectivas ações habitacionais, salienta-se que a política habitacional empreendida por Vargas não era um ato de generosidade e preocupação com as questões sociais gratuitamente. Na verdade, visava-se alimentar o sistema de permanência do Presidente no poder, ou seja, mostrava-se para o povo a 
preocupação do governo brasileiro no atendimento de suas necessidades habitacionais em troca de apoio político. Em suma, a política "varguista" atendia os anseios da classe dominada e agradava, substancialmente, a classe dominante que lucrava com os empreendimentos alugados. Esse fato evidencia o poder político que a arquitetura pode desempenhar numa sociedade. Como já dizia Juhn Ruskin, ao criticar a conduta da burguesia para com os operários em plena revolução industrial, "a arquitetura é uma arte essencialmente política e é imprescindível ao arquiteto trabalhar com a convicção de que as nossas instituições são realmente esplêndidas" (apud ARTIGAS, 1986, p. 71).

Entre os anos de 1937 a 1964, a produção dos IAPs em conjunto com os da Fundação da Casa Popular (FCP) produziram um total de 140,989 mil unidades habitacionais, sem contar os financiamentos realizados pela classe média (BRUNA, 2015). Além disso, ao longo dos anos a participação dos arquitetos brasileiros no processo de implementação de uma cultura de HIS no país, apesar de todas as dificuldades enfrentadas pela categoria em relação ao prestígio dos Engenheiros Civis, foi marcante, a ponto de nomes como Attilio Correia Lima (autor do Conjunto Residencial Várzea do Carmo em São Paulo de 1942 - |API), Carlos Frederico Ferreira (autor do primeiro bloco habitacional moderno do Conjunto do Realengo no Rio de Janeiro - IAPI), Eduardo Knesse de Melo (autor do Conjunto Residencial Rua Japurá em São Paulo de 1947 - IAPI), Flávio Marinho Rego (autor do Conjunto Residencial em Deodoro no Rio de Janeiro de 1953 - FCP), Paulo Antunes Ribeiro (autor do Conjunto Residencial da Mooca em São Paulo, de 1946 - IAPI), entre tantos outros, terem marcado a história da HIS.

Enquanto um grupo de profissionais de arquitetura lutavam pela efetivação de uma arquitetura voltada para o trabalhador industrial nas cidades, outros profissionais ligados ao ensino, lutavam pela institucionalização de um autônomo curso de arquitetura, desvinculado das tradicionais Escolas Politécnicas e Belas Artes. Essa autônima, passa a se efetiva a partir de 1945, quando é criado a Faculdade Nacional de Arquitetura (FNA) com o propósito de "ministrar o ensino de arquitetura e de urbanismo, visando à preparação de profissionais altamente habilitados; realizar estudos e pesquisas nos vários domínios técnicos e artísticos, que constituem objeto de seu ensino" (BRASIL, 1945, p.1).

A nova Faculdade mantinha dois cursos seriados, arquitetura e urbanismo. No entanto, tanto os catedráticos professores quanto o modelo curricular da ENBA foram incorporados a FNA. Esse currículo tornou-se modelo para a implantação dos demais cursos de arquitetura da época no país, ou seja, se oficialmente a questão da HIS não estava legitimado no currículo da ENBA, a partir da criação da FNA, essa ausência se amplia a nível nacional. Esse fato apenas reforça que a prática de sala de aula guiada por um "currículo informal" se fragiliza substancialmente, tendo em vista não haver registros de que o tema em questão era abordado nos ateliês.

Diante da situação ora exposta, questiona-se: No afã da luta por uma autonomia das escolas de arquitetura, os agentes envolvidos na formação da FNA teriam se descuidado da questão curricular e de seus conteúdos? Será que a seleção dos temas e disciplinas não teriam sido, propositalmente, revistas? Indiscutivelmente, um dos grandes problemas na transição da ENBA para a FNA se encontrava na seleção das disciplinas e temas que deviam ser contemplados, isso reflete e mostra muito sobre 
a visão de mercado dos que se envolveram no processo. Diante do aproveitamento curricular, elenca-se uma nova pergunta: Que tipo de profissional se buscava formar? Possivelmente a resposta para essa pergunta, esteja evidente no currículo da FNA, que vigorou para as escolas de arquitetura no pais, sejam elas reorganizadas ou criadas, até 1962:

"O currículo estabelecido para o Curso de Arquitetura da Faculdade Nacional de Arquitetura foi distribuído por 23 cadeiras com a seguinte seriação: $1^{\circ}$ ano: Matemática Superior; Geometria Descritiva; História da Arte; Desenho Artístico e Arquitetura Analítica (10 Parte). $2^{\circ}$ ano: Mecânica Racional; Sombras, Perspectiva e Estereotomia; Materiais de Construção; Teoria da Arquitetura; Arquitetura Analítica (2a parte); Composição de Arquitetura (1 ${ }^{a}$ parte). $3^{\circ}$ ano: Resistência dos Materiais e Estabilidadas Construções; Técnica da Construção e Topografia; Física Aplicada; Composição Decorativa; Composição de Arquitetura (2a parte). $4^{\circ}$ ano: Concreto Armado; Legislação e Economia Política; Higiene da Habitação e Saneamento das Cidades; Arquitetura no Brasil; Grandes Composições de Arquitetura (1 ${ }^{a}$ parte). $5^{\circ}$ ano: Sistemas Estruturais; Organização do Trabalho e Prática Profissional; Urbanismo e Arquitetura Paisagista; Grandes Composições de Arquitetura (2ª parte)" (ABEA, 1977, p. 56, grifo nosso).

No novo currículo da FNA, conforme Sanches (2005), as únicas disciplinas inéditas são as de Mecânica Racional, Concreto Armado e Arquitetura no Brasil. Algumas disciplinas foram reformuladas, mas a maioria permaneceu inalterada. Vale salientar que, quando da efetivação da FNA, a arquitetura moderna e a questão da "casa mínima" já havia se legitimado oficialmente; a própria casa popular já havia sido "[...] reconsiderada, glosada, estudada por muitos arquitetos, sob todos os aspectos possíveis e imagináveis, em todos os países" (ARTIGAS, 1986, p. 74); o I Congresso Brasileiro de Arquitetos, realizado em 1945, havia colocado em discussão central a defesa da função social do arquiteto; e, principalmente, a produção de HIS pelos IAPs estavam se efetivando gradativamente no cenário urbano das grandes cidades. O que se evidencia com esse modelo nacional de currículo para o ensino de arquitetura e urbanismo, é que ocorreu, intencionalmente, (des)encontros com a realidade profissional e a vivência acadêmica, ou seja, as demandas habitacionais pelos segmentos de menores rendimentos da sociedade brasileiras, até o momento, não foram seguidas de uma composição curricular apropriada.

\section{A reprodução do modelo não superado}

3 A partir dos anos de 1950, algumas faculdades importantes no país são criadas: criação da Faculdade de Arquitetura da Universidade do Rio Grande do Sul em 1952, criação da Faculdade de Arquitetura da Universidade Federal de Pernambuco em 1958, e criação da Faculdade de Arquitetura da Universidade Federal da Bahia em 1959. Todas essas faculdades foram criadas a partir do movimento separatista dentro das Escolas de Belas Artes.
Passado o momento de busca por uma autonomia, fortificação do prestígio social dos arquitetos e urbanistas, e da expansão dos cursos de arquitetura pelo Brasil ${ }^{3}$, inicia-se, a partir da segunda metade de 1950, uma movimentação nacional (entre docentes, discentes e profissionais liberais) com o intuito de rever as premissas, condutas e objetivos do ensino de arquitetura, visto que o currículo vigente, modelo da FNA, nada mais era do que uma junção de disciplinas de cunho artísticos com disciplinas técnicas.

Parte dos profissionais que consideravam importante a reformulação curricular, defendiam a inserção dos preceitos da arquitetura moderna, com mais incisividade nos bancos escolares, visto que, como relata Edgar Graeff, o ensino se mostrava muito resistente a novas perspectivas, principalmente de arquitetos pioneiros como 
Le Corbusier e Frank Lloyd Wrigh (GRAEFF, 2003 apud MONTEIRO, 2007, p.78). Por outro lado, havia um grupo que era contrário a essa inserção.

A postura contrária à inserção da Arquitetura Moderna no ensino é, claramente, expressa no comentário de Artigas (1986), quando relata que a arquitetura moderna brasileira se prestava a serviço de uma demagogia desenfreada - se referindo a preocupação declarada dos simpatizantes do movimento com a produção de uma arquitetura popular - e na sombra dos Institutos, durante o Estado Novo. Além disso, na visão do autor, as ideias modernas foram acriticamente aceitas pelo movimento estudantil, fruto das constantes propagandas tendenciosas feita fora e dentro do país.

Na busca por uma reformulação curricular, algumas experiências foram cruciais para se chegar a formulação de um documento apropriado. Uma dessas experiências foi a criação Faculdade de Arquitetura da Universidade Nacional de Brasília (UNB). A experiência implantada na UNB, possibilitou que um grupo de arquitetos pudessem elaborar projetos arquitetônicos dentro da universidade (ABEA, 1977), assim, foi possível estabelecer uma conexão mais aproximada entre teoria e prática por meio da atividade de pesquisa. Além dessa experiência, a reforma curricular ocorrida na Faculdade de Arquitetura da Universidade de São Paulo (FAU-USP) em 1962, exerceu grande impacto entre as faculdades de arquitetura.

Salienta-se que os anos de 1960 no Brasil, começaram bastantes agitados: Jânio Quadros assumiu a Presidência da República em 1961, mas, após 7 meses renuncia cedendo lugar para seu vice João Goulart. Entre 1961 e 1964, ano em que Goulart é deposto e o regime de exceção é implantado no país, no que se refere a política habitacional direcionada à população de menores rendimentos, o governo, com muito esforço, consegue dar seguimento ao funcionamento da FCP - primeiro órgão federal responsável pela área da habitação e desenvolvimento urbano no país, cujo projeto englobava a construção de casas, o financiamento de obras de infraestrutura urbana, entre outras.

Quando a FCP foi criada, houve grande reação contra o órgão, justamente pelo fato de, no final do Estado Novo, o governo lançar a proposta de unificação dos IAPs em um único órgão, ou seja, o Instituto de Seguridade Social Brasileiro (ISSB) e transferir os fundos para a FCP (MANOEL, 2004). A movimentação política e institucional contra a efetivação da FCP ganhou também o apoio do setor da construção civil. Tanto o Instituto de Arquitetos do Brasil, quanto o Clube de Engenharia, compactuavam com as críticas feitas ao governo, de que o mesmo estava querendo iludir os trabalhadores,

4 Até 1960, haviam sido construídos 16.964 casas e 143 conjuntos residência. Além disso, destaca-se que: "[...] se privilegiavam os grandes centros urbanos, pois $68 \%$ das construções localizaram-se nas grandes cidades da época, ou seja, as de população superior a 50 mil habitantes. Mas isso não quer dizer que não se tenham contemplado os pequenos e médios núcleos, os quais foram beneficiados com $32 \%$ das edificações realizadas" (AZEVEDO; ANDRADE, 2011, p.15). oferecendo a casa como processo básico de acesso a moradia. No entanto, Bonduki (2014), salienta que esse pensamento era infundado pois o projeto da FCP era mais amplo.

Em termos quantitativos ${ }^{4}$, a FCP conseguiu produzir pouco mais de 18.000 unidades habitacionais durante seus 18 anos de existência (1946-1964), e foram poucos os trabalhadores de menor poder aquisitivo que conseguiram se privilegiar da produção de casas da FCP visto que, segundo Azevedo (1988), o processo de seleção dos trabalhadores para aquisição da casa, acabou sendo distorcido, e houve um favorecimento aos que possuíam influência política. A FCP se manteve ativa até o ano de 1964 quanto é criado o Banco Nacional de Habitação (BNH). 
No âmbito educacional, em dezembro de 1961 é sancionada a Lei de Diretrizes e Bases da Educação Nacional (LDB), a partir de então, os cursos oferecidos pelas instituições de ensino superior deveriam ser conduzidos por um currículo mínimo. Isso fez com que as esperanças e desejos de se efetivar melhorias no ensino de arquitetura e urbanismo, por parte dos que não concordavam com as posturas imprimidas no currículo da FNA, se acendessem.

O projeto do primeiro currículo foi apresentado à comunidade acadêmica em junho de 1962 durante o III Encontro de Diretores, Professores e Estudantes de Arquitetura em São Paulo. A proposta curricular devia representar as aspirações e desejos de todo um conjunto de mobilizações nacionais de estudantes e profissionais no que se referia a adequação da "[...] formação desenvolvida nas escolas às especificidades do exercício da profissão e da atuação do arquiteto e urbanista na própria sociedade" (SANTOS JUNIOR, 2001, p. 11).

Conforme relato de Graeff, percebe-se que a expectativa quanto aos impactos que o estabelecimento do currículo mínimo poderia ocasionar no ensino de arquitetura eram as mais benéficas, ou seja, era como se o currículo se tornasse numa ferramenta transformadora e capaz de potencializa novas experiencias didático-pedagógicas:

"[...] O currículo mínimo vinha abrir oportunidades de mudanças e experiências inovadoras, inclusive no sentido de colocar o ensino em sintonia com as realidades geográficas, sociais e culturais de cada região" (GRAEFF, 1995, p. 45).

O currículo mínimo, como sugestionado nos encontros nacionais de arquitetos, estudantes e professores, deveria especificar um mínimo de unidade indispensável à formação do arquiteto em âmbito nacional, e abrir margem para que as particularidades regionais pudessem sem implementadas, a fim de viabilizar a construção de um campo fértil para o ensino (ABEA, 1977). Contudo, contrariando as expectativas, o currículo mínimo foi aprovado de modo resumido, sem nenhuma justificativa sobre a estrutura e sobre os componentes curriculares nele expresso.

O primeiro currículo mínimo apontou, como atribuição da graduação, a formação generalista do arquiteto e urbanista, de modo a garantir que a formação não se procedesse de modo fragmentado em duas áreas especializadas. Além disso, o mesmo também enuncia a formação continuada do arquiteto em campos específicos por meio de atividades complementares (CONFEA, 2010). Entende-se que, o termo

5 Conforme o Parecer $n^{\circ} 336$ de 1962 (ABEA, 1977, p.72), as disciplinas do currículo mínimo são: Cálculo; Física Aplicada; Resistência dos Materiais e Estabilidade das Construções; Desenho e Plástica; Geometria descritiva; Materiais de Construção; Técnica da construção; História da Arquitetura e da Arte; Teoria da Arquitetura; Estudos Sociais e Econômicos; Sistemas Estruturais; Legislação, Prática Profissional e Deontologia; Evolução urbana; Composição Arquitetônica, de Interiores e de Exteriores; Planejamento. generalista, não deve apenas se restringir a questão de formação única entre arquiteto e urbanista, e sim promover na formação superior, a inserção de assuntos fundamentais para que o futuro profissional possa desempenhar suas funções de modo a atender às necessidades e anseios da população. Contudo, o que se evidencia no ensino de arquitetura precedido pelo currículo mínimo, é que sob o ponto de vista da demanda e questões sociais, o ensino se apresentou fragilizado, justamente pelo fato do mesmo não legitimar a inserção de conteúdo relacionado com a produção de HIS ou disciplina específica correlata, fato esse que pode ser conferido na grade curricular especificada no Parecer $n^{\circ} 336$, de $1962^{5}$.

A comissão responsável em elaborar o primeiro currículo mínimo, buscou colocar a disciplina de Composição Arquitetônica como sendo a principal disciplina da grade. Essa 
importância, incita um questionamento: O fato da disciplina se apresentar como uma "espinha dorsal" do curso, essa não deveria indicar o estudo direcionado a produção de HIS ao considerar o déficit habitacional e a demanda social? Ao contrário do objetivo que deveria atingir, o currículo mínimo não transparece os debates e propostas de reformulação do ensino oriundos dos congressos acadêmicos e profissionais que antecederam sua homologação, além disso, entende-se que o mesmo continuou reproduzindo o modelo que pretendia superar.

\section{A condição secundária da Habitação de Interesse Social}

Após a instauração da Ditadura Militar no Brasil, o cenário educacional passa a enfrentar intensas e obrigatórias mudanças em todos os níveis e, sobretudo, no ensino superior. Dentre os fatos que marcaram o sistema educacional e a área da arquitetura e urbanismo nesse período, pode-se elencar alguns fatos: o fechamento do Instituto Superior de Pesquisas para Planejamento, prisão e exílio de professores universitários; instauração de um clima de insegurança política que afetou o ambiente intelectual das instituiç̧ões de ensino; e frustação das expectativas em relação ao ideário modernista (CONFEA, 2010). O sucateamento das universidades públicas e a necessidade de um número maior de profissionais no mercado por conta da crescente urbanização no país, abrem aminho para que a iniciativa privada invista na criação de novos cursos de graduação.

Em termos de benefícios sociais para a população de menores rendimentos financeiros, - Golpe Militar de 1964 se tornou um pesadelo. Instaura-se no Brasil uma política econômica que passa a priorizar a concentração de renda e o atendimento das demandas das classes médias altas. Se antes, a preocupação, no meio acadêmico, com a HIS não era incisivamente presente no currículo de 1962, com a não priorização de investimentos voltados para a produção habitacional, a situação é ainda mais agravada. Como se não bastasse, em plena ditatura, ocorre a Reforma Universitária em 1968.

Nesse embalo, os cursos de arquitetura e urbanismo se multiplicaram, de modo a contribuiu para que as ideias de estabelecimento de uma arquitetura comprometida com as necessidades da população não se efetivassem. Conforme Santos Junior (2001), associada ao descaso e a falta de manutenção dos padrões de qualidade das universidades, a Reforma Universitária conseguiu fazer com que o ensino superior fosse tido como um produto mercadológico comandado pelas empresas privadas educacionais. Se o currículo de 1962 já havia sido aprovado sem grandes justificativas e não conseguiu garantir um ensino de qualidade no pais, cabia agora, aos que se preocupavam com a referida qualidade, lutar para reestabelecer a credibilidade afetada pela referida reforma. Um dos caminhos encontrados foi concentrar esforços para que um novo currículo, comprometido com efetiva transformação profissional, fosse aprovado.

Visando atender a Reforma Universitária, e ainda contrariando todo um corpo profissional preocupado com o aprofundamento dos debates em torno das atribuições e conhecimentos fundamentais para o arquiteto e urbanista, em 1969, é imposto no país a reformulação do primeiro currículo mínimo de 1962, fixado pela Resolução $n^{\circ}$ 3, de 25 de junho de 1969, do Conselho Federal de Educação (CFE) com base no Parecer n 384/69 elaborado pela Comissão Especial (CE) formada por Clóvis Salgado (Coordenador), Celso Kelly (Relator), Celso Cunha e José Borges dos Santos (BRASIL, 1969). 
${ }^{6}$ A nova grade curricular do segundo currículo mínimo, separava as disciplinas em Básicas e Profissionais, são elas: Matérias Básicas: Estética; História das Belas Artes e, especialmente História da Arquitetura e Artes no Brasil; Plástica; Desenho e outros meios de expressão; Matemática; Física; Estudos Sociais; Desenvolvimento Econômico, Social e Político do Brasil; problemas correlatos em Arquitetura e Urbanismo e Comunicação em massa. Matérias profissionais: Teoria da Arquitetura; Arquitetura Brasileira; Resistência dos Materiais; Materiais de construção, detalhes e técnicas de construção; Sistemas Estruturais; Instalações; Higiene de Habitação e Planejamento.
O novo currículo mínimo, reestruturou os antigos componentes curriculares de 1962 e traz de modo mais esclarecido as atividades e abordagens de temas considerados fundamentais para a formação em arquitetura e urbanismo. Sobre a estrutura das disciplinas, verifica-se um certo retrocesso no ensino, ou seja, houve a substituição das disciplinas de Evolução Urbana e Composição Arquitetônica (de Interiores e Exteriores) por uma única disciplina denominada de Planejamento, que consistia numa "atividade criativa aplicada, quer quanto à arquitetura das habitações e edifícios em geral, quer quanto a projetos de objetos (arquitetura interior), quer quanto às cidades e regiões (Planejamento Urbano e Regional)" (BRASIL, 1969) ${ }^{6}$. Segundo Elvan Silva (1998 apud SANTOS, 2002, p. 129), "O currículo mínimo da Resolução 03/69 era incompleto e imperfeito, pois omitia, por exemplo, a referência explícita à temática urbanística, utilizava expressões obsoletas como 'Higiene da Habitação' ou imprecisas como 'Planejamento Arquitetônico'".

Ainda conforme o Parecer $n^{\circ} 384 / 69$, no ensino da nova disciplina de Planejamento, temas como o estudo de residências populares era considerado programa específico, e poderiam ser abordados caso houvesse demanda por parte dos alunos e se a instituição disponibilizasse de recursos suficientes para tal ensinamento. O que se apreende do relatório da $C E$, é que se atribuiu pouca importância à produção habitacional direcionada para a população de menores rendimentos financeiros, que, no período, se processava em larga escala por parte do BNH. Dada a importância do tema da HIS e a atuação dos arquitetos no mercado de trabalho, considera-se que esse tema não deveria depender de nenhum fator extra para sua inserção como conteúdo obrigatório. Tal situação reforça a pouca importância e a histórica ausência do tema da HIS na formação "generalista", a nível de graduação.

Outro ponto interessante do relato expresso no Parecer $n^{\circ} 384 / 69$, diz respeito a questão das favelas, que se constituíam num dramático desafio à arquitetura. No entanto, na visão da CE essa dramaticidade não se refere à questão do estabelecimento do mínimo espaço habitável, a funcionalidade da habitação ou a inserção urbana, e sim à uma questão estética, ou seja, o desafio clamava por fórmulas inspiradas na ambientação artística como condição para que houvesse uma significação estática que representasse o calor humano (BRASIL, 1969). Porém, ao passo que a CE expressa tal pensamento, ao descreverem as abordagens que a disciplinas de planejamento deveria transmitir ao alunado, não conseguem efetivar o desafio supracitado como elemento fundamental no currículo. Para não afirmar que esse fato se apresenta como um erro intencional, no mínimo, pode ser considerado como um fato incongruente.

Com a universidade pública desvalorizada, e com a imposição do segundo currículo mínimo, o ensino de arquitetura e urbanismo sofre sérias consequências. Entre elas, pode-se destacar: o estabelecimento da formação de profissionais limitados a servir ao sistema produtivo vigente, ou seja, destinado à elite dominante; formação maciça de profissionais vindos das instituições privadas que visavam maior lucro em detrimento da qualidade educacional, entre outras. Toda essa situação reforça o descomprometimento das universidades e do mercado produtivo com as questões sociais e, sobretudo, com a produção habitacional para os trabalhadores populares. Sobre a situação vivenciada no ensino de arquitetura, Santos Junior destaca: 
O distanciamento progressivo da educação escolarizada do arquiteto e urbanista das candentes demandas sociais - com graus variados do ponto de vista teórico-conceitual, da atualização tecnológica e da atuação prática - acabou por tornar rarefeita e episódica a contribuição oferecida pelas escolas às questões sociais que contam com imediato interesse profissional, como, por exemplo, aquelas relacionadas com a habitação ou com as intervenções na cidade (SANTOS JUNIOR, 2001, p. 14, grifo nosso).

Ademais, após a imposição do segundo currículo mínimo, evidentemente cumprindo com as exigências políticas educacionais do período, em 1974, a Associação Brasileira de Ensino de Arquitetura (ABEA) publica o relatório sobre o $1^{\circ}$ Encontro de Diretores de Escolas de Arquitetura do País, onde se evidencia o interesse pela reformulação do segundo currículo mínimo nacional vigente, visava-se que o mesmo abordasse tanto a formação do arquiteto, quanto a atuação do profissional no mercado de trabalho. Um dos pontos de destaque no referido Relatório (ABEA, 1974), é o registro da convocação do BNH feita aos diretores das escolas de arquitetura para a realização de concursos voltado aos estudantes dos últimos semestres, visando o incentivo pela elaboração e estudo de HIS, de modo que fosse considerado o Plano Nacional de Habitação Popular (PLANHAP). Apesar do currículo vigente considerar que o ensino voltado ao tema da HIS deveria se proceder em programas específicos, ou seja, não fundamental, impulsionado pela demanda social, o próprio BNH tratou de suprir a carência, e estimular o estudo e a pesquisa a nível de universidade, como caminho para familiarizar os futuros arquitetos com os problemas habitacionais brasileiros. Tal iniciativa, se apresentou como uma grande oportunidade das escolas de arquitetura e urbanismo no país, ao estabelecer novos caminhos curriculares, de implementarem mudanças nas contundas tradicionais arraigadas na graduação. Entretanto, essas possíveis mudanças não se efetivaram com facilidade nos anos seguintes.

Por fim, coaduna-se com a afirmativa de Maragno (2013, p. 155) ao se referir à carta de ouro preto de 1977, que o currículo mínimo de 1969 "[...] não era garantia, por si só, de melhoria do ensino, mas que ele poderia ser um indutor importante na melhoria do ensino e que sua reformulação era tarefa necessária e urgente".

\section{Oportunidades perdidas?}

"Mas, é claro que, enquanto a ligação entre os arquitetos e as massas populares não se estabelecer, não se organizar, enquanto a obra dos arquitetos não tiver a suma glória de ser discutida nas fábricas e nas fazendas, não haverá arquitetura popular" (ARTIGAS, 1986, p. 79, grifo do autor).

Sob o ponto de vista do ensino de arquitetura e urbanismo, evidencia-se na fala de Vilanova Artigas, a lacuna existente entre a formação dos arquitetos e sua relação com as demandas sociais. Esse é, provavelmente, o maior desafio do ensino de arquitetura e urbanismo no Brasil, ou seja, construir uma ponte sólida entre a formação teóricoprática com as questões relacionadas à produção habitacional, direcionada à população sem e com os menores rendimentos financeiros da sociedade. Pelo que foi apresentado neste artigo, o tema da HIS foi tratado de modo distinto ao longo dos anos, desde a primeira reformulação curricular ocorrida na ENBA, até a constituição do segundo currículo mínimo dos cursos de Arquitetura e Urbanismo, no ano de 1962. 
A primeira manifestação curricular que se tem registro na historiografia do ensino de arquitetura, cuja reforma marcou a trajetória dos cursos no Brasil, é o da ENBA, em 1931. Naquela ocasião, as forças políticas e as influências internacionais sobre a produção arquitetônica no país, contribuíram para que Lúcio Costa, mesmo a contragosto por parte de muitos professores, efetivasse um ensino de cunho tecnicista e influenciado pelas concepções modernistas. Esta teria sido a primeira oportunidade onde o tema da HIS poderia ter sido incluído, oficialmente, no ensino dos futuros profissionais de arquitetura, mas, essa acabou por não se efetivar. A responsabilidade dessa efetivação, ficou atribuída, numa espécie de "currículo informal", aos professores, que por sua vez, poderiam ou não, abordar o referido tema nos ateliês. Ao se considerar a marcante resistência dos clássicos catedráticos da ENBA em relação aos ideais modernos - cujos principais nomes haviam se debruçado sobre o estudo do habitar mínimo -, podese apontar que o ensinamento dos estudos citados, não deve ter se procedido com grande abertura.

Quatorze anos após a reforma curricular da ENBA, no ano de 1945, a criação da FNA no Rio de Janeiro, conseguiu concretizar a desejada autonomia dos cursos de arquitetura e urbanismo, resultado do esforço de profissionais e estudantes comprometidos com a causa. As expectativas em relação às mudanças na formação dos novos profissionais da arquitetura e urbanismo voltado para uma compreensão mais ampla dos problemas da construção no país, foram, parcialmente, frustradas. Quando se instituiu da FNA, o currículo que se tornou modelo para todo o território nacional, não se desvinculou, totalmente, das antigas posturas e tradições das Escolas Politécnicas e ENBA. Aquele momento, que compõe os fatos históricos dos primeiros currículos mínimos de arquitetura e urbanismo, poderia ter sido a segunda oportunidade do tema da HIS se concretizar como disciplina ou conteúdo obrigatório na graduação de arquitetura e urbanismo, principalmente se for considerado as influências das políticas públicas de enfrentamento ao aumento do déficit habitacional no país, e a atuação de importantes arquitetos no envolvimento com os problemas e projetos de HIS. Contudo, restou à HIS, mais uma vez, ser omitida do ensino oficial de arquitetura e urbanismo.

As duas primeiras "oportunidades perdidas" apontadas anteriormente, exerceram influência nas ações curriculares ocorridas a posteriori no ensino de arquitetura e urbanismo no país. Se a realidade habitacional do país não conseguiu exercer influência para que a HIS fosse contemplada como uma responsabilidade fundamental do arquiteto nas condutas educacionais oficiais, as chances dessa ausência se perpetuar nas futuras reformulações curriculares eram altas. Em 1962, com a finalidade de elevar o nível de qualidade do ensino de arquitetura e urbanismo, é aprovado o primeiro currículo mínimo nacional. Mas, lamentavelmente, a realidade passada se repetiu, ou seja, a terceira e, talvez, a mais promissora das oportunidades para que o ensino de arquitetura pudesse estabelecer intima conexão com as massas populares, não se efetivou oficialmente. Entretendo, acredita-se que, alguns professores, ligados à questão da HIS não deixaram de incorporar o respectivo tema em suas atividades nos ateliês, mesmo de modo extraoficial.

Foi apenas em 1969, em plena Ditadura Militar e implementação da Reforma Universitária, que, pela primeira vez, o tema da HIS aparece oficialmente no documento curricular dos cursos de arquitetura e urbanismo no Brasil. O Parecer n 384/69, que serviu de base para a aprovação do segundo currículo mínimo, elege o tema da HIS 
como um programa específico e o considera como integrante do campo de atividade do arquiteto. No entanto, o segundo currículo mínimo, ao listar os conteúdos das disciplinas, atribui ao ensino sobre a produção de HIS prerrogativas para que sua efetivação no ateliê ocorresse, o que, de certo modo, se tornou um obstáculo para a implementação do conteúdo. Conforme foi evidenciado no artigo, o surgimento dessa quarta oportunidade para que a HIS, oficialmente, entrasse no currículo, foi parcialmente concretizada. Enquanto o currículo de 1962, intencionalmente, negligenciou a abordagem do conteúdo como prioritário, o currículo mínimo de 1969, legitima a condição secundária da inserção do referido tema no curso de graduação em arquitetura e urbanismo, e o coloca em condição de programa específico, ou seja, que deve ser alcançado pelo profissional por meio dos cursos de formação continuada, as conhecidas pós-graduações.

A explanação apresentada evidencia que, o modo como os currículos foram estruturados, ao longo da história, principalmente até o ano de 1962, imprimiu-se uma cultura de exceção na abordagem das questões referentes à HIS no ensino de arquitetura e urbanismo e consequentemente, na formação "generalista" do futuro profissional. Como exceção, restou ao referido tema, ser trabalhado em programas específicos de formação continuada se, ainda assim, a instituição desenvolvesse este tipo de atividade e linha de pesquisa.

Os fatos históricos expostos, confirmam que a ausência da inserção do tema da HIS nos cursos de graduação em arquitetura e urbanismo, como já assinalado pelos pesquisadores do tema, é, também, consequência histórica da condição secundária no qual foi posto os estudos sobre HIS nos primeiros documentos oficiais que balizaram as condutas pedagógicas do ensino de arquitetura e urbanismo no Brasil. Para que essa realidade seja, enfaticamente, modificada, é preciso que os cursos de graduação em arquitetura e urbanismo, construam estratégias para que a formação profissional não fique restrita apenas ao atendimento das necessidades da população com as mais elevadas rendas, e passem a formar profissionais críticos e com visão centrada no equacionamento dos problemas espaciais das aglomerações urbanas, das residências populares, dos assentamentos informais, ou seja, o arquiteto urbanista do século XXI.

Continuar considerando o tema da HIS como uma especialização do campo de atuação do arquiteto, é contribuir, indiretamente, com a progressiva desigualdade social que destrói progressivamente nossas cidades, além de reforçar uma arquitetura voltada para uma classe dominante específica. Por fim, coaduna-se com a afirmativa de Ferreira (2011, p. 2-3, grifo nosso) o qual relata que "esse "mundo" da habitação de interesse social, da informalidade urbana (generalizada), simplesmente parece não pertencer ao "mundo" da arquitetura".

\section{Referências bibliográficas}

ABEA. Boletim, da ABEA, no 1. 1974. Disponível em: <http://www.abea.org.br/?page_id=739>. Acesso em: 20 dez. 2015.

ABEA. Sobre a história do ensino de arquitetura no Brasil. São Paulo, Associação Brasileira de Arquitetura, 1977. 
ARAVECCHIA BOTAS, Nilce Cristina. Entre o progresso técnico e a ordem política: arquitetura e urbanismo na ação habitacional do IAPI. Tese (Doutorado) - Universidade de São Paulo - USP. Faculdade de Arquitetura e Urbanismo, São Paulo, 2011.

ARTIGAS, João Batista Vilanova. Caminhos da arquitetura. $2^{\circ}$ ed. São Paulo: Pini, Fundação Vilanova Artigas, 1986.

AZEVEDO, Sérgio de. Vinte e dois anos de política habitacional (1964-86): criação, trajetória e extinção do BNH. Revista de Administração Pública, Rio de Janeiro, v. 22, n. 4, p. 107119, 1988.

AZEVEDO, Sérgio de; ANDRADE, Luís Aureliano Gama de. Habitação e Poder: Da Fundação da Casa Popular ao Banco Nacional Habitação. Rio de Janeiro: Centro Edelstein de Pesquisas Sociais, 2011. Disponível em: <http://static.scielo.org/scielobooks/xnfq4/pdf/ azevedo-9788579820557.pdf>. Acesso em: 25 jul. 2016.

BASTOS, Maria Alice Junqueira; ZEIN, Ruth Verde. Brasil: Arquiteturas após 1950. São Paulo: Ed. Perspectiva, 2010

BENETTI, Pablo. Habitação Social e Cidade. 1. ed. Rio de Janeiro: Rio Book's, 2012.

BONDUKI, Nabil. Habitação e Arquitetura Moderna no Brasil: a produção dos IAPs (1937/64). In: Seminário de História da Cidade e do Urbanismo, 1994. Revista SHCU 1990, v. 3, n. 3, p. 1-31, 1994

Os pioneiros da habitação social no Brasil: volume 01. $1^{\circ}$ ed. São Paulo: Editora Unesp: Edições Sesc São Paulo, 2014.

BRASIL. Decreto $n^{\circ} 19.852$, de 11 de abril de 1931. Dispõe sobre a organização da Universidade do Rio de Janeiro.

DecretoLei n. 7.918 - de 31 de agosto de 1945. Dispõe sobre a organização da Faculdade Nacional de Arquitetura da Universidade do Brasil.

Parecer n³84/69 - de 10 de junho de 1969. Currículo Mínimo de Arquitetura.

BRUNA, Paulo Júlio Valentino. Os Primeiros Arquitetos Modernos: Habitação Social no Brasil 1930-1950. $1^{\circ}$ ed. 1 reimpr. São Paulo: Editora da Universidade de São Paulo, 2015.

CAVALCANTI, Lauro Pereira. Moderno e brasileiro: a história de uma nova linguagem na arquitetura, (1930-60). Rio de Janeiro: Jorge Zahar Ed., 2006.

CONFEA. Trajetória e estado da arte da formação em engenharia, arquitetura e agronomia volume X: Arquitetura e Urbanismo. Conselho Federal de Engenharia, Arquitetura e Agronomia. - Brasília: Instituto Nacional de Estudos e Pesquisas Educacionais Anísio Teixeira; Conselho Federal de Engenharia, Arquitetura e Agronomia, 2010. v.10.

FERREIRA, João Sette Whitaker. Perspectivas e desafios para o jovem arquiteto no Brasil. Qual o papel da profissão? Arquitextos, São Paulo, ano 12, n. 133.07, Vitruvius, jul. 2011. Disponível em: <http://www.vitruvius.com.br/revistas/read/arquitextos/12.133/3950>. Acesso em: 30 jul. 2015.

GRAEFF, Edgar Albuquerque. Arte e Técnica na Formação do Arquiteto. São Paulo. Studio Nobel/Fundação Vilanova Artigas. 1995.

MANOEL, Sálua Kairuz. Fundação da Casa Popular (1946-1964): projeto frustrado de construção de habitação de interesse social no Brasil. Dissertação (Mestrado) - Escola de Engenharia de São Carlos, Universidade de São Paulo, São Carlos, 2004.

MARAGNO, Gogliardo Vieira. A Associação Brasileira de Ensino de Arquitetura e as relações entre o ensino de Arquitetura e Urbanismo e a habilitação profissional no Brasil. In: MONTEIRO, Ana Maria Reis Goes; et al (org.). A construção de um novo olhar sobre o ensino de arquitetura e urbanismo no Brasil: os 40 anos da Associação Brasileira de Ensino de Arquitetura e Urbanismo. Brasília: ABEA, 2013, p.138-166. 
MONTEIRO, Ana Maria Reis de Góes. O ensino de Arquitetura e Urbanismo no Brasil: a expansão dos cursos no Estado de São Paulo no período de 1995 a 2005. Tese (Doutorado) Universidade Estadual de Campinas. Pós-Graduação em Engenharia Civil, Campinas, São Paulo, 2007.

SANCHES, Maria Ligia Fortes. Construções de Paulo Ferreira Santos: a fundação de uma historiografia da arquitetura e do urbanismo no Brasil. Rio de Janeiro, 2005. 511 f. (Doutorado/ História Social da Cultura) - Programa de Pós-graduação em História Social da Cultura, Pontifícia Universidade Católica do Rio de Janeiro.

SANTOS JUNIOR, Wilson Ribeiro dos. O currículo mínimo no ensino de arquitetura e urbanismo no Brasil: 1969 -1994. Tese (Doutorado) Universidade Estadual de São Paulo. Pós-Graduação em Arquitetura e Urbanismo, São Paulo, 2001.

SANTOS, Roberto Eustaáquio dos. Atrás das grades curriculares: da fragmentação do currículo de arquitetura e urbanismo no Brasil. Dissertação (Mestrado) Universidade Federal de Minas Gerais, Escola de Arquitetura. Pós-Graduação em Arquitetura e Urbanismo, Belo Horizonte, 2002.

SEGAWA, Hugo. Arquitetura no Brasil 1900-1990. 3 ed. São Paulo: Editora da Universidade de São Paulo, 2010. (Acadêmica; 21).

SOUZA, Abelardo. Arquitetura no Brasil: depoimentos. São Paulo: Diadorim - Universidade de São Paulo, 1978. 